\title{
High Strength Opioid Formulations in Ontario: By the Numbers
}

\section{A Report by the Ontario Drug Policy Research Network}

\section{SCOPE OF THE ISSUE:}

Recently announced Ontario Drug Benefit (ODB) program changes to reimbursement for high-strength long-acting opioids have elicited much discussion regarding their potential impact and implications in palliative care. The ODPRN conducted a rapid-analysis to inform current discussions on the utilization of these formulations in the ODB and their usage among palliative care patients.

Table 1: Prevalence of High Strength Opioid Tablets and Patches in FY2014/15

\begin{tabular}{|c|c|c|}
\hline Opioid & $\begin{array}{c}\text { Long-acting Tablets/Patches* } \\
\mathbf{N}\end{array}$ & $\begin{array}{c}\text { High Strength Formulations } \\
\mathbf{N}(\%)\end{array}$ \\
\hline Overall & $\mathbf{4 2 , 4 0 3 , 6 5 3}$ & $\mathbf{4 , 4 9 0 , 1 9 6 ( \mathbf { 1 0 . 6 } \% )}$ \\
\hline Morphine & $14,533,986$ & $288,411(2.0 \%)$ \\
\hline Fentanyl & $2,557,504$ & $1,223,735(47.9 \%)$ \\
\hline Hydromorphone & $25,312,163$ & $2,978,051(11.8 \%)$ \\
\hline
\end{tabular}

Table 2: Patterns of High Strength Opioid Users and Prevalence of Palliative Care in FY2014/15

\begin{tabular}{|l|c|}
\hline Opioid Users & $\mathbf{N}(\%)$ \\
\hline Users of long-acting opioids* & $\mathbf{8 7 , 4 5 3}$ \\
\hline Users of high strength formulations & $13,695(15.7 \%)$ \\
\hline High strength opioid users with palliative care in prior $\mathbf{6}$ months & $1,349(9.9 \%)$ \\
\hline
\end{tabular}

*morphine, fentanyl, or hydromorphone

Table 3: Opioid Use among Palliative Care Patients in Ontario in FY2014/15

\begin{tabular}{|l|c|}
\hline Palliative Care Patients & $\mathbf{N}(\%)$ \\
\hline Number of palliative care patients in Ontario & $\mathbf{6 2 , 6 0 2}$ \\
\hline Palliative care patients with any opioid reimbursed by ODB & $26,620(42.5 \%)$ \\
\hline Palliative care patients with any high strength opioid* reimbursed by ODB & $1,673(2.7 \%)$ \\
\hline
\end{tabular}

*morphine, fentanyl, or hydromorphone

\section{BRIEF METHODOLOGICAL DETAILS:}

Study Period: April 1, 2014 to March 31, 2015

High Strength Opioid Formulations:

Hydromorphone: $24 \mathrm{mg}$ and $30 \mathrm{mg}$; Morphine: $200 \mathrm{mg}$; Fentanyl $75 \mathrm{mcg} / \mathrm{hr}$ and $100 \mathrm{mcg} / \mathrm{hr}$

Palliative Care: Defined using OHIP fee codes for palliative care services, or inpatient hospitalizations with a palliative care patient service. 


\section{ACKNOWLEDGMENTS}

This study was supported by St. Michael's Hospital (SMH) and the Institute for Clinical Evaluative Sciences (ICES), which is funded by an annual grant from the Ontario MOHLTC. The opinions, results and conclusions reported in this paper are those of the authors and are independent from the funding sources. No endorsement by SMH, ICES or the Ontario MOHLTC is intended or should be inferred.

We thank IMS Brogan Inc for use of their Drug Information Database. Parts of this material are based on data and information compiled and provided by $\mathrm{ClHI}$. However, the analyses, conclusions, opinions and statements expressed herein are those of the author, and not necessarily those of $\mathrm{CIHI}$. 